\title{
Effect of Subcutaneous Fat of Quadriceps Muscle on Q-Angle - A Cross-Sectional Study
}

\section{Jagruti K Patel*, Maldikar Pragna Satish, Patel Harsh Vinodbhai and Vaidya Nikita Rakeshkumar}

S.S. Agrawal Institute of Physiotherapy and Medical Care Education, Devina Park Society, Gujrat, India

*Corresponding Author: Jagruti K Patel, Assistant Professor, S.S. Agrawal Institute of Physiotherapy and Medical Care Education, Devina Park Society, Gujrat, India.
Received: June 23, 2020

Published: June 30, 2020

(C) All rights are reserved by Jagruti K

Patel., et al.

DOI: $10.31080 /$ ASOR.2020.03.0192

\begin{abstract}
Background: Q-angle is an important indicator of the biomechanical function for the lower extremity. The increased value of Q-angle is suggestive of risk factors for many knee disorders. The fat is considered as basic compound of body which is necessary for certain anatomical and physiological functions. The accumulation of excess body fat affects the musculoskeletal system.

Purpose: This study was conducted to determine the co-relation between the Q-angle and subcutaneous fat of the Quadriceps muscle and also determine the normal value of Q-angle and normal value of the Skinfold thickness of the Quadriceps Muscle.

Procedure: A cross-sectional study was conducted among 109 individuals, having no history of knee injury or pain. There were 59 females and 50 males participated in the study. The Q-angle was measured in standing position with the help of universal goniometer and the Quadriceps muscle was kept relaxed. The measurement of the skinfold thickness was taken by normal plastic skin calliper. Results: The study showed that mean value of the Q-angle for females and males on the right side was $16.9 \pm 1.85$ and $13.87 \pm 1.95$ whereas on left side it was obtained $16.9 \pm 1.85$ and $13.96 \pm 2.01$. The study also obtained the mean value of the subcutaneous fat of quadriceps for females and males on right side $14.0 \pm 5.16$ and $11.22 \pm 5.30$ whereas on left side it was obtained $13.9 \pm 5.15$ and 11.54 \pm 5.37 . The study also obtained positive co-relation among the Q-angle and Quadriceps fat. $(\mathrm{p}=0.001)$.

Conclusion: The study concluded that there was a positive co-relation among the Q-angle and subcutaneous fat of the Quadriceps muscle.
\end{abstract}

Keywords: Quadriceps Angle; Subcutaneous Fat; Quadriceps Muscle

\section{Abbreviations}

Q-Angle: Quadriceps Angle; Q-Fat: Quadriceps Muscle Fat; WHO: World Health Organization; ASIS: Anterior Superior Iliac Spine

\section{Background}

The KNEE joint falls under the category of CONDYLAR variety of SYNOVIAL joint, stabilised by muscles and ligaments [1]. It is most often injured joint in the body. The knee joint works alongside ankle joint and hip joint to support body weight in static erect posture and in dynamic state it is responsible to move and support body during both routine and challenging activities [2].

The Knee complex is composed of two distinct articulation located within single joint capsule:

- $\quad$ Tibio-femoral joint

- $\quad$ Patello-femoral joint

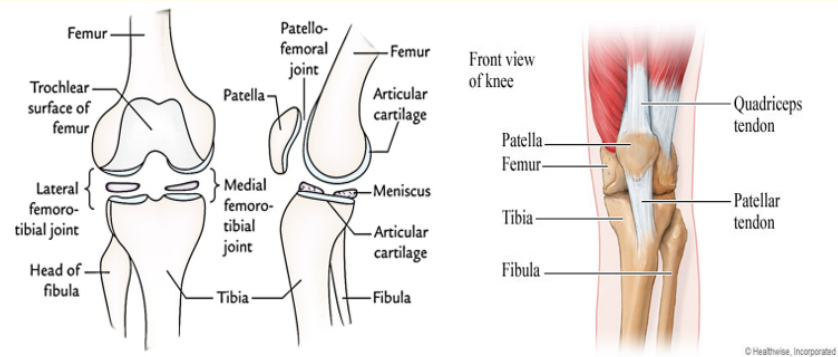

Figure 1: Knee joint complex

This complex joint gets involved in about $50 \%$ of musculoskeletal injuries and dysfunctions in which involvement of patellofemoral joint is most common. The important indicator for the alignment of the patellofemoral joint is Q-angle or Quadriceps angle. 
Q-angle is also termed as Quadriceps angle. BRATTSTROM was the first person who defined Q-angle. The angle which is formed between the ligamentum patellae and extension of the line formed by Quadriceps muscle having resultant force at apex of patella is considered as Q-angle. It is created by intersection of two imaginary lines.

- $\quad$ First line drawn from Anterior Superior Iliac Spine (ASIS) to the centre of patella.

- Second line drawn from tibial tuberosity to the centre of patella [3].

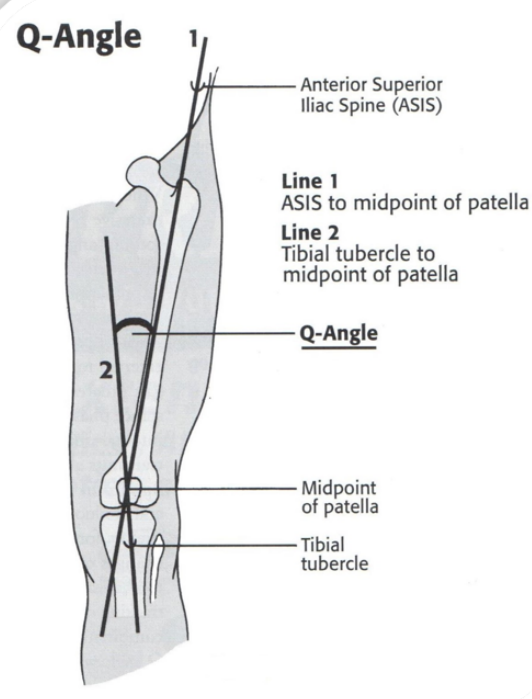

Figure 2: Landmarks of Q-angle.

The measurement of Q-angle is considered as key indicator of biomechanical function in the lower extremity. It represents the effect of Quadriceps mechanism on the knee. Q-angle is considered as the diagnostic measurement to access the factors which appear to increase risk for occurrence of acute and chronic knee pain or injury. The normal value of the $\mathrm{Q}$-angle should fall under the range of $12^{\circ}$ to $20^{\circ}$; where usually females are at higher end and males having lower values. Generally, the values greater than $20^{\circ}$ is considered as excessive [4]. The increased Q-angle is considered as risk factors for many disorders such as patellar subluxation, dislocation, patellofemoral joint pain, chondromalacia patella etc.

Q-angle can be assessed with the help of various methods such as radiographic imaging (i.e. X-ray, computed topography etc.), surface photographic imaging and surface goniometry [5]. The study conducted by Mohammed Faisal concluded that there was significant correlation among the Q-angle obtained by goniometry method and X-ray imaging method $(p=0.001)$. The study deter- mined that the goniometric measurement of $Q$ angle was as effective and accurate as of radiographic measurement. Moreover, it has a benefit that subject is not exposed to radiation [6].

There are no accepted standards kept for measuring the Qangle. There has always been debate regarding determination of bony landmarks and placement of markers on the skin. In clinical practice Q-angle is generally measured with help of long arm goniometer, positioning subject either in standing or supine position. However, the accuracy of the measurement depends upon the goniometer, the skill ability of the tester and the clarity of knowledge regarding the procedure.

Q-angle can be measured in either supine or standing position. But the conditions in which abnormal $Q$ angles are assumed are conditions of weight bearing. Therefore, the value of $Q$ angle in supine position which is an asymptomatic position is of less use. Thus, the standing position is more useful position for measurement of the $Q$ angle [7]. Moreover, while measuring the angle in standing position requires relaxed Quadriceps muscle and placement of feet forward and together. As this position determines the normal weight at the knee joint during regular day activities [8]. However, most of the authors suggest for supine position but no exact position is stated. As per Turkmen, the standing $Q$ angle measurement is found to indicate more physiological basis. The standing position determines more appropriate functional position [9]. Islam Tarawneh conducted a study by measuring $Q$-angle in standing position and obtained the excellent intra-observer and inter-observer reliability of having correlation value ranging from 0.74 to 0.83 [8].

The changes in the muscle mass, muscle power, muscle endurance, flexibility and joint range of motion leads to affection in the musculoskeletal system [10]. Moreover, the system also gets affected due to weight and level of the obesity [11].

Body composition relates to general health status. Anthropometry, Body Mass Index, subcutaneous fat, fat mass etc. are terms used for describing and measuring the value of body composition. Body composition is used for determination of the percentages of fat, bone and muscle in human bodies [12]. Fat is considered as basic compound of body which is necessary for certain anatomical and physiological functions. Person's morbidity and mortality is affected by the content of fat [13]. Muscular tissue takes less space in our body as compared to fat tissue [12].

According to the Behke's theoretical model for body composition, the reference MAN is considered as taller and heavier where his skeleton weighs more having large muscle mass and lower body fat content than the reference WOMEN [6]. 


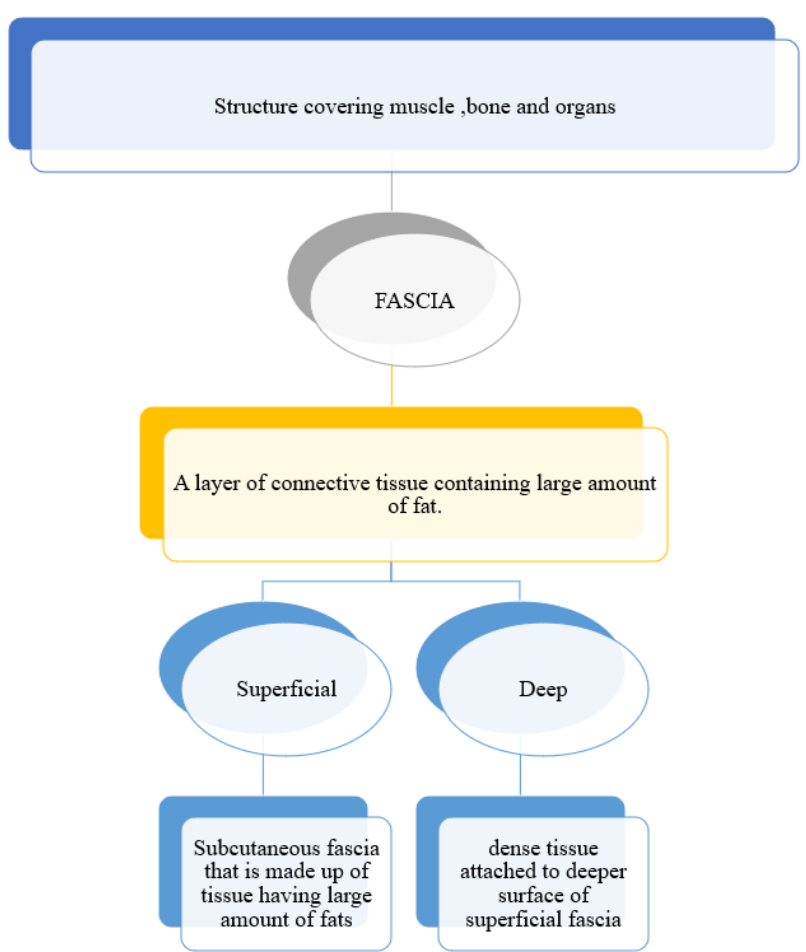

Figure a

Around $50 \%$ of the total amount of body fat is comprised of fat tissue. Based on this fact, the measurement of the skinfold thickness of the subcutaneous tissue could provide important information regarding the body composition. Subcutaneous fat tissue is primarily the adipose tissue that lies beneath the skin.

Generally, the techniques of measuring body composition is by chemical analysis of the human cadaver, hydrostatic weighing, anthropometric measurement or by clinical or laboratories methods [6]. Technological techniques such as computerized tomography, magnetic resonance imaging or dual X-ray absorptiometry are also used [14].

Mostly, "laboratory" methods are not adequate for field and clinical usage. Therefore, anthropometric methods are widely used in clinical and field area. Mainly when there is large sized population, no proper availability of the economic resources and need for the quick measure [15].

Anthropometry, where anthropo is termed as human and metry as measure [6]. It is considered as a standardized technique as per Who (World Health Organization), comparing to other procedures, this procedure is less expensive as well as harmless method for evaluating the size, proportion and composition of the human body [14] and also one of the fundamental tools for assessing nutritional sufficiency [16].
The skinfold thickness is one of the variable of anthropometry [17] which is frequently considered as "bed side" or "field" method for body composition measurement in clinical studies [15]. It is considered that Skinfold measure the subcutaneous fat whereas the circumferences measure the girths [6].

The skinfold thickness is regarded as body fatness predictor. It is so because it measures $40 \%-60 \%$ of total body fat i.e. is subcutaneous fat with the help of skin caliper [18]. The inter-relation between following 3 factors provides the major reason for using skinfold:

- Adipose tissue which is directly beneath the skin.

- Internal fat of the body

- Whole-density of the body. i.e. whole-body density

The CALIPERS mainly pincer type helps to measure subcutaneous fat accurately at anatomical sites. This calipers operate on principle similar to micro-meter which calculates distance among two points. Skinfold thickness measure by firm grasping of the skin and subcutaneous fat with the help of thumb and forefinger pulling away the under lying muscle tissue.

Adolescence is the period of life where major changes among body composition takes place. Gender and pubertal stage are major factors which impact the quantity of body fat-mass along as well as its distribution pattern [15]. Moreover, the accumulation of excess body fat affects the musculoskeletal system [11]. Thus, the purpose of the study was to determine whether the subcutaneous fat accumulated by the Quadriceps muscles affects the Q-angle and to determine the normal values of $\mathrm{Q}$-angle and skinfold thickness among healthy individuals.

\section{Methods}

Study design: A Cross sectional study.

Study setting: Study was conducted in physiotherapy department of NEUROLOGY, S.S. Agrawal Institute of Physiotherapy, Navsari, Gujarat, India.

Study population: Healthy young Adults - age group (17 - 25 years).

Study duration: 6 months.

Sampling method: Convenient sampling.

Population size: 150 .

Sample size: The sample size formula described by "Yamane" is:

$$
n=\frac{N}{1+N(e) 2}
$$


Where:

$\mathrm{N}=$ Same size

$\mathrm{N}=$ Population

$\mathrm{E}=$ Significance level

$1=$ Unit.

\section{Inclusion criteria}

- $\quad$ Young healthy adults within the age of 17 - 25 years

- $\quad$ Subjects of both gender

- $\quad$ Subjects who were willing to participate

- $\quad$ Asymptomatic subjects

\section{Exclusion criteria}

- The subjects having history of Fracture of the lower limb, chronic knee pain.

- The subjects having history of dislocation of patellae and spine cord pathology with lower limb involvement.

- The subject having history of Anterior or retro-patellar pain.

- The subject having any history of surgery on the knee, clinical evidence of meniscal injury, ligamentous instability and patellar instability.

Materials

- A stadiometer to measure the standing height.

- A electrical body weight scale to measure body weight.

- A plastic universal goniometer to measure Q-angle.

- An indelible marker to mark the anatomical landmark.

- Flexible tape to measure femur length.

- Common plastic skinfold caliper to measure skinfold of the Quadriceps muscle.

- $\quad$ Record sheet.

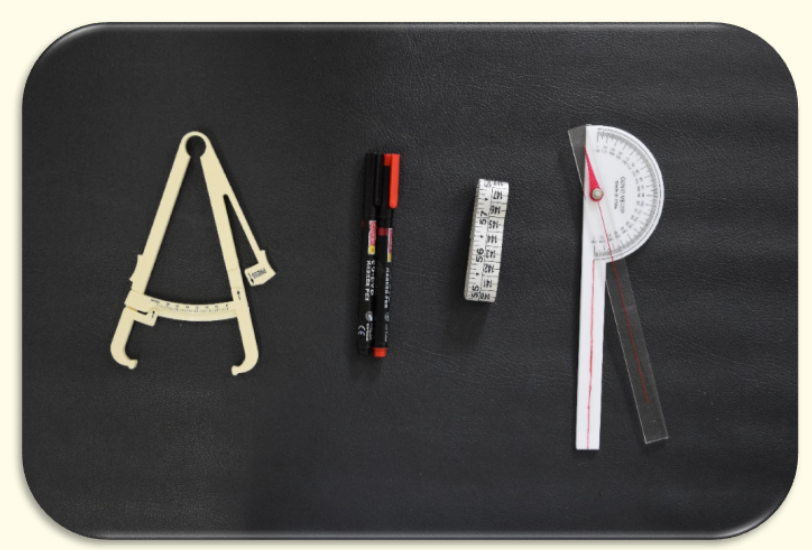

Figure 3: Common plastic skinfold-caliper, markers, measure tap, gonio-meter

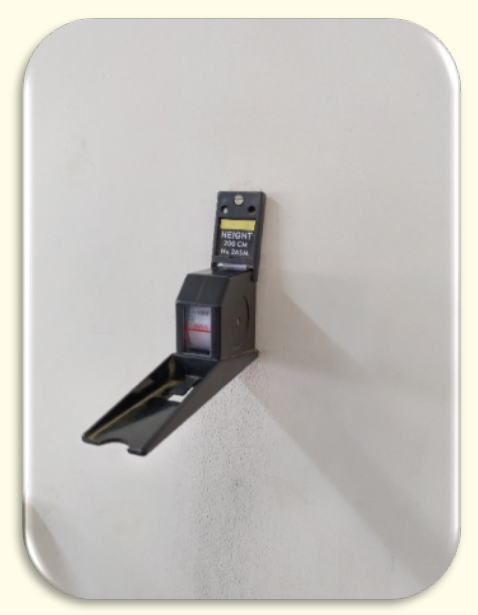

Figure 4: Stadiometer.

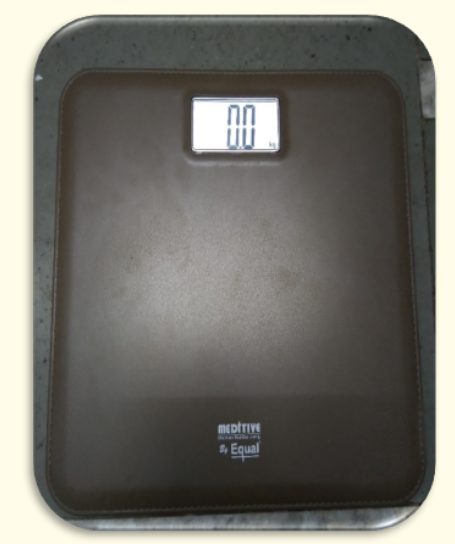

Figure 5: Electric body weight scale.

Tester

Study was conducted by the physiotherapy interns under the supervision of assistant professor of S.s Agrawal institute of Physiotherapy.

Procedure

The purpose and the procedure of the research was explained to the subjects. Based on the inclusion and exclusion criteria, the subjects were requested to participate in research. The participants willing to participate in the research were selected. The procedure was explained before starting the research and the consent form was also signed.

Procedure for measurement of the Q-angle

The description regarding the procedure was given to the subjects prior taking the measurement. The recording of data like age, height, weight and gender was done. Each subject was dressed in 
shorts and t-shirts the subject was decently exposed for the determination of the anatomical landmarks.

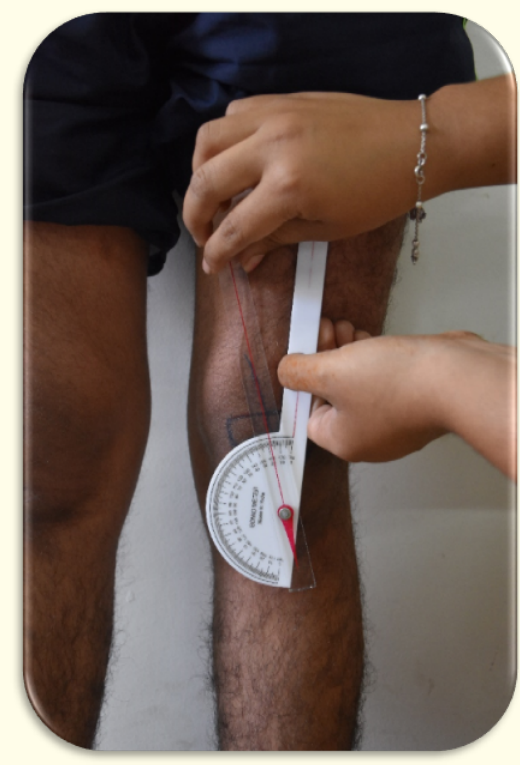

Figure 6: Measurement of Q-angle.

The subject was positioned in the standing (erect position) with barefoot supported to the wall. The anatomical landmarks such as border of the patella, tibial tubercle and anterior superior iliac spine were palpated and marked by the indelible marker. Also, the center of the patella was marked.

The axis of the goniometer was placed at the midpoint of the patella. The stationary arm placed on the ASIS and movable are was placed aligned to the tibial tubercle. This formed angle was read as the Q-angle. The Quadriceps muscle was kept relaxed throughout the measurement of the angle. All the measurement was taken by single examiner. The measurement was taken for 3 times and average value was taken as the final value of the angle

\section{Procedure for measurement skinfold of Quadriceps}

Measurement of the skinfold thickness required firmly grasping a fold of skin and subcutaneous fat with thumb and forefingers. Then pulling it away from the underlying muscle tissue as per the natural contour of the skinfold.

A pinch is taken as the vertical fold at the midline of the thigh. It is taken at the two thirds the distance from the middle of the patella to the hip. The caliper dial indicates the skinfold thickness in millimetre (mm) which is recorded within 2 seconds after applying the full force of caliper. This limitation of time at time of measurement. Minimum of three measurements is taken at site of body and average value is considered as the final value [12]

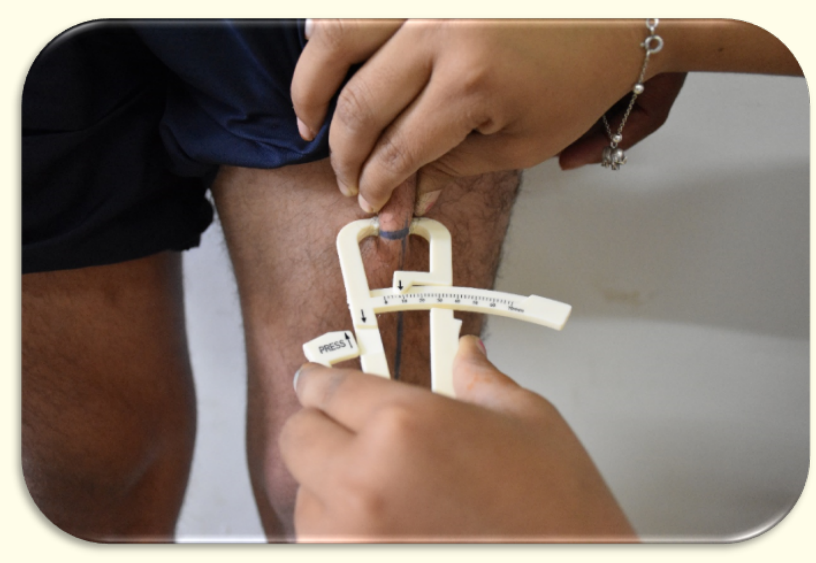

Figure 7: Measurement of Q-fat.

Data analysis

- Data collected were entered and analysed by SPSS (Statistical Package for the Social Sciences) 26.00 for windows (IBM).

- Descriptive statistics was used to analyses baseline characteristics of subjects.

- Results of the outcome measures were expressed as a summary measure (Mean \pm SD) and presented with appropriate tables.

- Pearson's co-relation was applied to find out the co-relation between the component of Q-Fat and Q-angle.

\section{Results}

Population chart

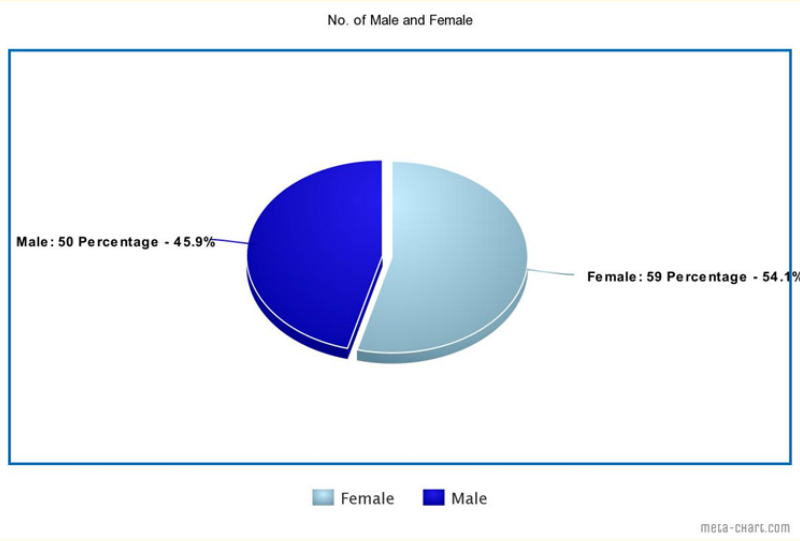

Chart 1: Population pie chart.

The total population taken for the study was 109. Above Pie chart 1 represent the sample size of the present research study. There were 50 male and 59 female participant taken for the study. 


\begin{tabular}{|l|c|c|}
\hline \multicolumn{3}{|c|}{ Descriptive Statistics } \\
\hline \multirow{3}{*}{ Age } & Mean & Std. Deviation \\
\cline { 2 - 3 } & 19.3945 & 2.05489 \\
\hline
\end{tabular}

Table 1: Mean and standard deviation of the age of the students.

The total population taken for the study was 109. In which participants of the study were of age category 17 - 25 years. The Mean age of the participants were 19.3945 and Standard Deviation were 2.05489 .

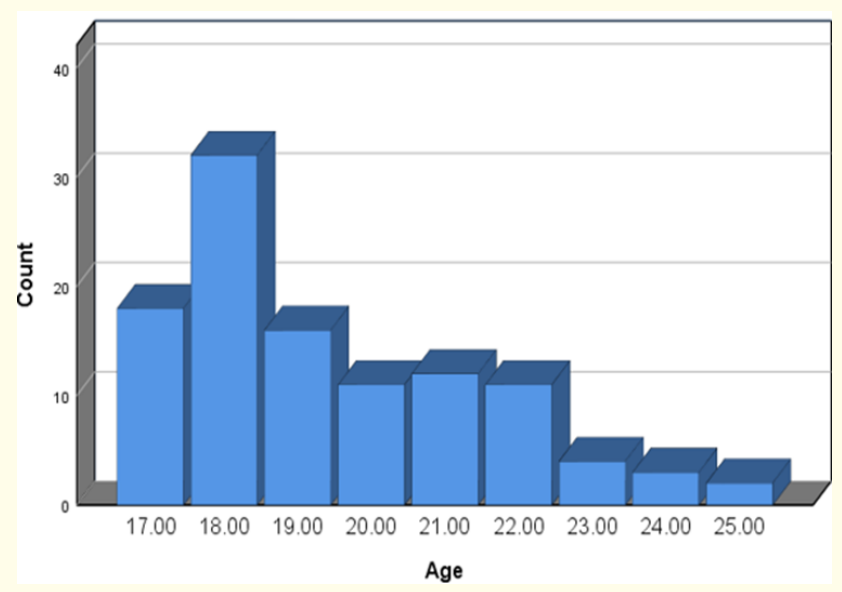

Graph 1: Baseline data for the age of the student.

\begin{tabular}{|l|c|c|}
\hline \multicolumn{3}{|c|}{ Descriptive Statistics } \\
\hline \multirow{2}{*}{ Height $(\mathrm{cm})$} & Mean & Std. Deviation \\
\cline { 2 - 3 } & 166.5257 & 8.74269 \\
\hline
\end{tabular}

Table 2: Mean and standard deviation of the height of the students.

The total population taken for the study was 109. In which Mean Height of the participants were $166.5257 \mathrm{Cm}$ and Standard deviation were 8.74269 .

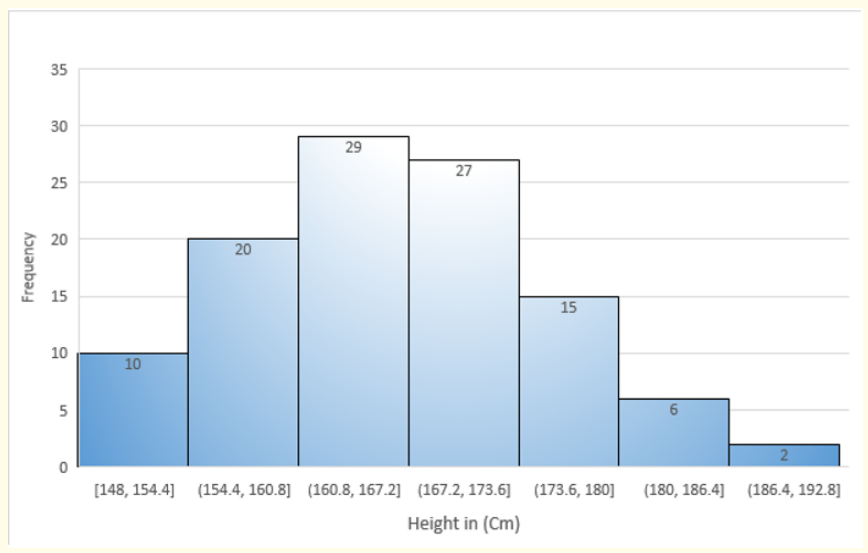

Graph 2: Baseline data for the height of the student.

\begin{tabular}{|c|c|c|}
\hline \multicolumn{3}{|c|}{ Descriptive Statistics } \\
\hline \multirow{3}{*}{ Weight $(\mathrm{Kg})$} & Mean & Std. Deviation \\
\cline { 2 - 3 } & 57.3541 & 13.71812 \\
\hline
\end{tabular}

Table 3: Mean and standard deviation of the weight of the students.

The total population taken for the study was 109. In which mean Weight of the participants were $57.3541 \mathrm{Kg}$ and Standard Deviation were 13.71812 .

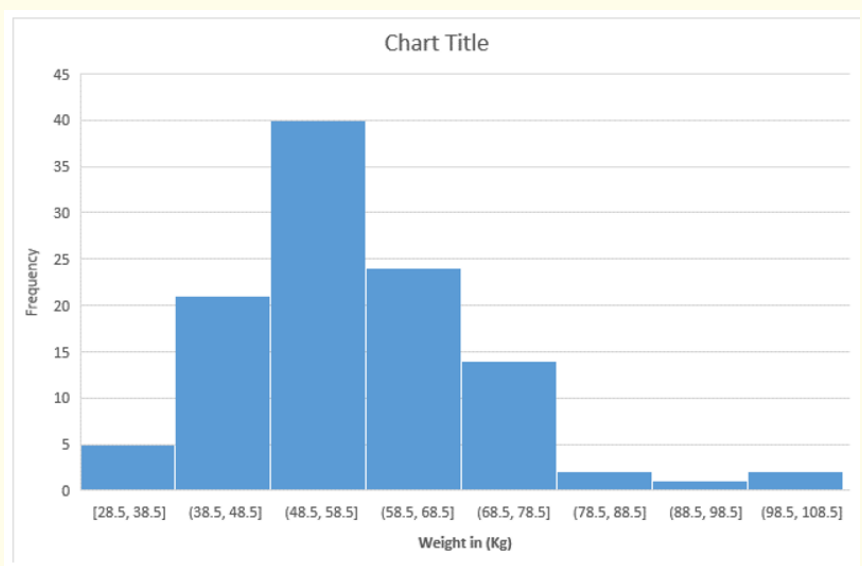

Graph 3: Baseline data for the weight of the student.

The above table shows highly positive co-relation between Quadriceps angle and subcutaneous fat of the Quadriceps muscle. The components were found to be highly significant $(p=0.001)$.

\section{Discussion}

The primary aim of the study was to determine the co-relation among the Q-angle and Subcutaneous fat of the Quadriceps muscle among the healthy individuals of age 17 - 25 Years. The measurement of the Q-angle and skinfold thickness of both the limbs were taken. The result of the present study showed that there was a strong positive co-relation among the values of the Quadriceps angle and subcutaneous fat of the Quadriceps muscle. The result obtained were highly significant.

The secondary aim of the study was to determine the normal value of the Q-angle among healthy population. However, several studies have been done in the literature to determine the value of the Q-angle. In present study the value obtained of Q-angle in right limb were $13.87^{\circ} \pm 1.95^{\circ}$ for male and $16.9^{\circ} \pm 1.85^{\circ}$ for female. For left limb the value was $16.9^{\circ} \pm 1.85^{\circ}$ for female and $13.96^{\circ} \pm$ $2.01^{\circ}$ for male. The mean values obtained in this study were higher 
than measurements recorded in other population which might be because of variations in the race. As the body height and weight might show variations with different ethnic origin [8]. The study conducted by islam tarawaneh among jordian population also found similar variations in there obtained values. Moreover, the higher values were obtained in females as compared to males which may be because of the women's broader pelvis, shorter femur length and more inwards twist of the femur [8].

The other aim of the study was to determine the value of subcutaneous fat thickness. According to the study done by Sahika Pinar, the values of skinfold thickness of the subcutaneous fat of the thigh region for males were $19.5 \pm 8.9$ whereas for females they obtained were $30.3 \pm 8.2$ [8]. In our present study, the values for males in right limb were $11.22 \pm 5.50$ and $14.0 \pm 5.16$ for females. For left limb value was $13.9 \pm 5.15$ in male and $11.54 \pm$ 5.37 in female. The obtained result shows greater variations might be because of variations in the body fat which is because of the variations of the physical activity, diet and ethnicity [8]. Also as per the literature states that the body fat varies from one individual to other as well as one part of the body to other [11].

The present study showed positive co-relation among Q-angle and Q-fat. This might be because increased content of the body fat leads to alterations in proportions of muscle tissue as well as body fats which influences the function of the muscle. As stated in the study done by Goodposter BH. Also, the subcutaneous tissue varies from one individual to other hampering alteration and body composition [11]. Thus, fat deposited in Quadriceps muscle might leads to change in Q-angle. Therefore, it might be considered that increased level of fat alters the angle of Quadriceps.

\section{Conclusion}

Young healthy individuals of 17 - 25 years showed positive corelation among the Q-angle and the subcutaneous fat of the Quadriceps muscle.

\section{Acknowledgement}

We would like to show our gratitude to the S.S Agrawal Institute of Physiotherapy and Medical Care Education for sharing their pearls of wisdom with us during this research. We are grateful to our subjects who participated enthusiastically and co-operated throughout the study.

\section{Conflict of Interest}

Nil.

\section{Bibliography}

1. Raveendranath Veeramani., et al. "The Quadriceps Angle (Q Angle) in Indian men and Women". European Journal of Anatomy 13.3 (2009): 105-109.

2. Levangie Pamela K and Cynthia C Norkin. "Joint Structure and Function". F.A. Davis (2011).

3. Chhabra Prabhjot Kaur., et al. "Quadriceps Angle": An Important Indicator of Biomechanical Function of Lower Extremity and Its Relation with Anterior Knee Pain". International Journal of Scientific Study (2016).

4. Khasawneh Ramada R., et al. "Measurement of the Quadriceps (Q) Angle with Respect to Various Body Parameters in Young Arab Population". PLOS One 14 (2019): e0218387.

5. Weiss Lawrence., et al. "Reliability of Goniometry-Based QAngle". PM\&R 5.9 (2013): 763-768.

6. McArdle William D., et al. "Exercise Physiology". Lippincott Williams \& Wilkins (2010).

7. Wilson Tony and Fleur Kitsell. "Is the Q-Angle an Absolute or a Variable Measure?” Physiotherapy 88.5 (2002): 296-302.

8. Tarawneh Islam., et al. "Normal Values of Quadriceps Angle and Its Correlation with Anthropometric Measures in a Group of Jordanians". Journal of the Royal Medical Services 23.2 (2016): 53-58.

9. Raizada Aprajita., et al. "Changes in quadriceps angle (q-angle) with regard to gender and different anthropometric parameters". International Journal of Anatomy and Research 7.3.1 (2019): 6756-6761.

10. Verma Chhaya., et al. "Study of Variation in Quadriceps Angle in Healthy Individuals". Scholars Journal of Applied Medical Sciences (SJAMS) (2018).

11. Anandacoomarasamy A., et al. "The Impact of Obesity on the Musculoskeletal System". International Journal of Obesity 32.2 (2007): 211-222.

12. Poblano-Alcalá Adriana and Debbie Braun-Zawosnik. "Differences among Somatotype, Body Composition and Energy Availability in Mexican Pre-Competitive Female Gymnasts". Food and Nutrition Sciences 05.06 (2014): 533-540.

13. Durnin JVGA and J Womersley. "Body Fat Assessed from Total Body Density and Its Estimation from Skinfold Thickness: Measurements on 481 Men and Women Aged from 16 to 72 Years". British Journal of Nutrition 32.01 (1974): 77-97. 
14. Akyer fiahika P`nar., et al. "Comparison of Ultrasonography and Skinfold Measurements of Subcutaneous Fat Thickness in the Evaluation of Body Composition". International Journal of Experimental and Clinical Anatomy (2014).

15. Rodríguez G., et al. "Body Fat Measurement in Adolescents: Comparison of Skinfold Thickness Equations with Dual-Energy X-Ray Absorptiometry". European Journal of Clinical Nutrition 59.10 (2005): 1158-1166.

16. Kavak Vatan. "The Determination of Subcutaneous Body Fat Percentage by Measuring Skinfold Thickness in Teenagers in Turkey". International Journal of Sport Nutrition and Exercise Metabolism 16.3 (2006): 296-304.

17. Nordhamn K., et al. "Reliability of Anthropometric Measurements in Overweight and Lean Subjects: Consequences for Correlations between Anthropometric and Other Variables". International Journal of Obesity 24.5 (2000): 652-657.

18. Goodpaster Bret H. "Measuring Body Fat Distribution and Content in Humans". Current Opinion in Clinical Nutrition and Metabolic Care 5.5 (2002): 481-487.

\section{Assets from publication with us}

- Prompt Acknowledgement after receiving the article

- Thorough Double blinded peer review

- Rapid Publication

- Issue of Publication Certificate

- High visibility of your Published work

Website: https://www.actascientific.com/

Submit Article: https://www.actascientific.com/submission.php

Email us: editor@actascientific.com

Contact us: +919182824667 